from which the stimulus is derived; and also to produce noun responses rather than responses of other form-classes-e.g., among the syntagmatic associations to adjectives there are more than twice as many nouns as there are responses of other form-classes.

There have been several discussions of the determinants of the form-class of word associations in the literature. Ervin (1961) derives an explanation for pardigmatic responses in adults in terms of the association-theory explanation for the production of syntagmatic responses. Syntagmatic responses of the type "deep-hole" can be explained in terms of experience of words in contiguity. Paradigmatic responses of the type "deep-shallow" can be accounted for by erroneous anticipation of "shallow" in the sort of lexical contexts which contain "deep." This explanation has been shown inadequate by McNeill (1966). It is, moreover, difficult to see how the explanation as it stands can account for the variation between stimuli of different form-classes in the likelihood of eliciting syntagmatic responses. Deese (1962) accounts for this variation in terms of the relative "independence of their verbal environments" of words of different form-classes: nouns, for instance, are relatively independent, while low-frequency adjectives depend more heavily on the environments which they modify.

McNeill's (1966) explanation of form-class matching is based on Deese's (1964) observation that paradigmatic associations form a minimal contrast with the stimulus, and on a dictionary-entry theory of semantics of the sort proposed originally by Katz \& Fodor (1963): each lexical item is characterized by an entry containing syntactic and semantic markers, and selection restrictions. $\mathrm{McNeill}$ argues that word associations are attempts to match the stimulus on as many features as possible, including syntactic features. This explanation also fails to account for variations between words of different form-class in the likelihood of eliciting paradigmatic responses; nor is the tendency to produce noun responses very well accounted for. However, the tendency for transformed words to elicit associations matching the form-class of the bases from which they are derived can be accounted for, if it is assumed that the dictionary entry for, say, the nominalization of an adjective comprises an entry for the adjective, plus, at some level, an entry for the transforming suffix.

The preference for noun responses has been considered by Marshall \& Newcombe (1966) in a study of paralexic errors in reading single words. In Marshall and Newcombe's study, where the form-class of the word was incorrectly given, there was a tendency for the erroneous word to be a noun rather than a word of another form-class. Chomsky (1965) has suggested that, in the theory of syntax, nouns are first inserted into generalized phrase-markers by context-free rules, and then verbs and adjectives are selected in accordance with the noun features. Marshall and Newcombe suggest that this argument may be applied not only to sentence production, but also to paralexic errors in single-word reading; it could also be extended to word association to account for noun-response dominance. It might even account for the differences between words of different form-class in the likelihood of eliciting paradigmatic responses. In essence, the argument may be reduced to something very like Deese's suggestion that nouns are less context-dependent than other parts of speech.

To summarize: The form-class of associations obtained in this experiment can be accounted for by the proposition that associations are attempts to match the stimulus on syntactic and semantic features. When the stimulus is a nominalization or an adjectivalization, there is a compromise between the form-class of the stimulus and the form-class of the underlying base, supporting the notion that nominalizations and adjectivalizations are coded in terms of a base and a transforming suffix. Where form-class matching breaks down, there is a regression towards noun responses.

\section{REFERENCES}

BRIEM, J., \& LOEWENTHAL, K. Immediate recall of nominalizations and adjectivalizations. Psychonomic Science, 1968, 11, 209.

CHOMSKY, N. Syntactic structures. The Hague: Mouton, 1957.

CHOMSKY, N. Aspects of the theory of syntax. Cambridge: M.I.T. Press, 1965.

DEESE, J. Form class and the determinants of association. Journal of Verbal Learning \& Verbal Behavior, 1962, 1, 79-84.

DEESE, J. The associative structure of some common English adjectives. Journal of Verbal Learning \& Verbal Behavior, 1964, 3, 347-357.

ERVIN, S. M. Changes with age in the verbal determinants of word association. American Journal of Psychology, 1961, 74, 36 1-372.

KATZ, J. J., \& FODOR, J. The structure of a semantic theory. Language, 1963, 39, 170-210.

McNEILL, D. A study of word-association. Journal of Verbal Learning \& Verbal Behavior, 1966,6, 548-557.

MARSHALL, J. C., \& NEWCOMBE, F. Syntactic and semantic errors in paralexia. Neuropsychologia, 1966, 4, 169.

SAVIN, H. B., \& PERCHONOK, E. Grammatical structure and the immediate recall of English sentences. Journal of Verbal Learning \& Verbal Behavior, 1965, 4, 348-353.

THORNDIKE, E. I., \& LORGE, I. The teacher's book of 30,000 words. New York: Columbia University Press, 1944.

\title{
Effect of concept grouping and dominance level on free recall
}

DENNIS M. ROBERTS and BIKKAR S. RANDHAWA, Department of Measurement and Evaluation, The Ontario Institute for Studies in Education, Toronto 5, Ontario, Canada

Lists of words were developed from Underwood \& Richardson's (1956) verbal concept formation materials that would vary (1) in terms of their overall dominance level, and (2) whether or not words within lists were related to the same adjective concept. In administering these lists in a repeated measures design, no main effects (dominance level or concept grouping) were found, but a highly significant interaction resulted. It appears that concept grouping of words into lists only facilitates words of low dominance level.

Scandura (1967) has recently shown that varying the dominance level of Underwood \& Richardson's (1956) concept formation materials results in differential recall. King, Reid, \& Roberts (1966) have shown that when lists of words are composed of different alternation patterns of dominance level, odd-shaped serial-position curves are obtained. It was also reported that no significant differences in recall were obtained when the lists of words were or were not grouped on the basis of having all words within the same list related to the same sense-impression adjective category. The previous evidence tends to support the notion that dominance level may be related or analogous to such measures as association value or Noble's (1952) $\bar{m}$. The present study was designed to further investigate whether the amount of free recall is a function of dominance level, and whether grouping nouns into concept-related or nonconcept-related lists affects recall.

\section{SUBJECTS}

Subjects were 72 psychology students at Ryerson Poly technical Institute in Toronto, Canada. The sample was predominantly male. Four separate classroom sections were used. 
Table 1

Lists of Words

\begin{tabular}{|c|c|c|c|c|c|c|c|}
\hline $\mathrm{HC}$ & Dom $\%$ & $\mathbf{L C}$ & Dom. \% & $\mathrm{HNC}$ & Dom.\% & LNC & Dom. \% \\
\hline \multicolumn{2}{|c|}{ List 1} & \multicolumn{2}{|c|}{ List 3} & \multicolumn{2}{|c|}{ List 5} & \multicolumn{2}{|c|}{ List 7} \\
\hline Knob & 68 & Carrot & 6 & Blood & 91 & Cabin & 39 \\
\hline Doughnut & 71 & Tongue & 8 & Ammonia & 88 & Tobacco & 23 \\
\hline Spool & 74 & Eel & 15 & Bed & 76 & Money & 9 \\
\hline Globe & 95 & Harpoon & 16 & Village & 74 & Silk & 39 \\
\hline Head & 66 & Straw & 11 & Germ & 84 & Armor & 23 \\
\hline Wheel & 94 & Icicle & 15 & Dandelion & 85 & Tar & 44 \\
\hline Balloon & 55 & Alley & 16 & Grass & 88 & Seaweed & 49 \\
\hline \multicolumn{2}{|c|}{ List 2} & \multicolumn{2}{|c|}{ List 4} & \multicolumn{2}{|c|}{ List 6} & \multicolumn{2}{|c|}{ List 8} \\
\hline Bandage & 73 & Gorilla & 42 & Ether & 70 & Asphalt & 27 \\
\hline Teeth & 72 & Ocean & 33 & Gnat & 76 & Pony & 48 \\
\hline Snow & 71 & Ape & 30 & Night & 90 & Moccasin & 53 \\
\hline Napkin & 62 & Camel & 14 & Blush & 96 & Sauerkraut & 24 \\
\hline Chalk & 80 & Zoo & 32 & Atom & 87 & Brick & 46 \\
\hline Ivory & 64 & Hog & 20 & Ivy & 83 & Ginger & 11 \\
\hline Milk & 83 & Forest & 12 & Corn & 81 & Needle & 9 \\
\hline
\end{tabular}

\section{MATERIALS}

Some of Underwood and Richardson's verbal concept formation materials based on sense-impression descriptive-adjective associations made to concrete nouns were used in the present study. In their study, the percen tage of Ss who classified a given noun into the same adjective category was called the noun's dominance level for that particular adjective concept. Eight sevenitem lists were currently developed as discussed below, defining as high dominance, words that had values of $55 \%$ or greater while low dominance was defined as words with less than $55 \%$.

Two lists (HC) utilized nouns of high dominance level within the same concept categories of round and white. These were formed by selecting categories in which more than seven high-dominance nouns could be obtained. No words in either of the $\mathrm{HC}$ lists had any interitem associations with words from the other $\mathrm{HC}$ list or both LC lists according to the Underwood and Richardson tables.

Two lists (LC) used low-dominance words and the concept categories of large and long. Words within each of the LC lists had no stated interitem associations with the other LC list or words in the HC or LNC lists.

Two lists (HNC) were formed using high-dominance words from categories other than those used in the HC and LC lists so that words within a list would not be related to the $\mathrm{HC}$ or $\mathrm{LC}$ words or related to other words within each HNC list. Due to

Table 2

Means and Standand Deviations for $\mathrm{HC}, \mathbf{L C}$, HNC and LNC Conditions

\begin{tabular}{llll}
\hline $\begin{array}{l}\text { Concept } \\
\text { Grouping }\end{array}$ & & \multicolumn{2}{c}{ Dominance Level } \\
\cline { 3 - 4 } & & High & Low \\
\hline \multirow{2}{*}{ Concept } & $\overline{\mathrm{X}}$ & 8.96 & 9.22 \\
& SD & 1.90 & 1.92 \\
No concept & $\overline{\mathrm{X}}$ & 9.50 & 8.75 \\
& SD & 1.81 & 1.79 \\
\hline
\end{tabular}

the increasing restrictiveness of the selection of words, however, two words within each HNC list had the same concept category classification. Also, the two HNC lists had words from many of the same concept categories.

Two final lists (LNC) were developed using low-dominance words and nonconcept category grouping. Words were first included that had no stated interitem associations to any of the categories already used in the other lists. Since only three words met this criterion, other words were selected that had only one association to another concept category. Categories other than those used in the HC or LC lists were utilized to select words with the above characteristics. Also, these lists were made up of words with their one interitem category association being evenly distributed over the already used concept categories. Table 1 presents the eight lists values.

In summary, there were two $\mathrm{HC}$ lists of words that were of high-dominance level with each word within a list being related to a common descriptive adjective (concept) category, two LC lists composed of words of low-dominance level with each list again being related to a common concept, two HNC lists using high-dominance words without having the words within a list being related to the same concept category, and two LNC lists where words were of low dominance without having words within a list related to the same concept category.

\section{PROCEDURE}

A repeated-measures design was used whereby all Ss received all eight lists. All words were presented individually on transparencies via a Carousel projector. The seven items in a list were flashed consecutively with approximately $2 \mathrm{sec}$ being allowed between one stimulus being presented and viewed, and the next stimulus being presented. After all items had been along with their published dominance flashed, a blank slide would appear allowing $30 \mathrm{sec}$ recall time. Ss were instructed that the words did not have to be written down in the same order as they appeared. The order of presentation for the eight lists was randomly determined for each of the four classes to counterbalance possible proactive effects. It is recognized, however, that this particular design does not control for possible selection-multiple treatment interference interactions (Campbell \& Stanley, 1963).

\section{RESULTS AND DISCUSSION}

The dependent variable was the number of words correctly recalled summed across both lists in each of the HC, LC, HNC, and LNC categories. Thus, each $\mathrm{S}$ received four scores and each score could range from 0-14 (seven words in each of two lists). Table 2 presents the means and standard deviations for the $\mathrm{HC}, \mathrm{LC}, \mathrm{HNC}$, and $\mathrm{LNC}$ conditions. The results of the ANOV with repeated measures (Winer, 1965, p. 319) on the dominance and concept grouping factors showed no significant main effects (dominance level, $F=2.20$, n.s., df $=1,71$; concept grouping, $F<1$, n.s., $\mathrm{df}=1,71$ ). However, the interesting finding in the present study was the highly significant interaction $(F=7.50, p<.01, d f=1,71)$. In examining the means, it seems as though the retention of words not grouped in concept categories is facilitated when the words are of high dominance levels while the concept grouping tends to facilitate the retention of low dominance-level words. The present data tentatively suggest that concept grouping facilitates free recall but that its effect may be restricted to lower dominance-value words. However, the above results should be interpreted with caution due to the exploratory nature of the study using the newly constructed lists of words. Future studies, using the presently developed materials where randomization of Ss to conditions is possible, and better experimental control will be required before definite conclusions can be drawn.

\section{REFERENCES}

CAMPBELL, D. T., \& STANLEY, J. Experimental and quasi-experimental designs for research. In N. L. Gage (Ed.), Handbook on research on teaching. Chicago: Rand-McNally, 1963.

KING, F. J., REID, I., \& ROBERTS, D. M. Free 'recall of intralist items as a function of serial position, association value and conceptualization. Psychonomic Science, 1966, 4, 311-312.

NOBLE, C. E. An analysis of meaning. Psychological Review, 1952, 59, 421-430.

SCANDURA, J. Concept dominance in short-term memory. Journal of Verbal Learning \& Verbal Behavior, 1967, 6, 461-469.

UNDERWOOD, B. J., \& RICHARDSON, J. Some verbal materials for the study of concept formation. Journal of Experimental Psychology, 1956, 53, 84-95.

WINER, B. J. Statistical principles in experimental design. New York: MoGraw-Hill, 1962. 